\title{
Opinion of hospital pharmacy practitioners toward the Continuing Pharmacy Education program: a study from a tertiary care hospital in central Nepal
}

This article was published in the following Dove Press journal: Integrated Pharmacy Research and Practice

22 September 2017

Number of times this article has been viewed

\section{Ramesh Sharma Poudel' \\ Rano Mal Piryani \\ Shakti Shrestha ${ }^{3}$ \\ Roshan Chaurasiya' \\ Bed Prakash Niure'}

'Hospital Pharmacy, Chitwan Medical College Teaching Hospital, Chitwan, Nepal, ${ }^{2}$ Health Professionals Education and Research Centre, Chitwan Medical College Teaching Hospital, Chitwan, Nepal, ${ }^{3}$ Department of Pharmacy, Shree Medical and Technical College, Chitwan, Nepal
Correspondence: Ramesh Sharma Poudel Hospital Pharmacy, Chitwan Medical College Teaching Hospital, PO Box 42, Bharatpur-10, Chitwan, Nepal

Tel +97756526632

Email poudel.ramesh@cmc.edu.np
Background: Meeting participants' needs and matching their preferences are important prerequisites for an effective Continuing Pharmacy Education (CPE) program. The objective of this pilot study was to assess the opinion of hospital pharmacy practitioners with respect to the CPE program.

Methods: The pretested questionnaires were distributed to 20 pharmacy practitioners working in a pharmacy at a tertiary care hospital in Nepal which asked for their opinions and suggestions with respect to the CPE program. Descriptive statistics were performed using IBM SPSS version 20.

Results: Topics related to skills development (75\%) and recent innovations in pharmacy practice (65\%) were mostly preferred. Live (in-person) presentations ( $80 \%$ ) and small group discussion $(60 \%)$ were the most suitable methods for delivery. Improving knowledge $(75 \%)$, improving skills $(60 \%)$ and keeping up-to-date in the latest information $(60 \%)$ were major motivating factors to participate, while lack of time $(75 \%)$ was a major barrier. Approximately $55 \%$ of the participants believed that face-to-face interview was a suitable method for evaluating the effectiveness. Allocation of separate time for the program, assessing baseline knowledge and skills of the participants along with delivery of quality materials in an understandable way were the top common suggestions for improving the CPE program.

Conclusion: Hospital pharmacy practitioners' opinions and suggestions were assessed with respect to the CPE program and this was upgraded accordingly to meet their expectations.

Keywords: continuing education, opinion, pharmacy, pharmacy practitioner, Nepal

\section{Introduction}

Competency of pharmacy practitioners is a prerequisite for patient-centered care, which can be strengthened through improvement of knowledge, skills and performance in a sustainable manner. ${ }^{1,2}$ Continuing Pharmacy Education (CPE) is a means to achieve this objective. The fundamental elements of CPE program include selfdirected, structured and outcome-oriented activities for practice-based learning. ${ }^{3}$ This long-lasting process is accompanied by reflection, planning, action and evaluation. ${ }^{4,5}$ Most countries with a CPE system share features of mandatory annual or fixed-term involvement in personal development activities. ${ }^{6,7}$ However, it is not obligatory for pharmacy practitioners in Nepal.

Significant transformations have been observed in the roles and responsibilities of pharmacy practitioners because of advancement in technologies, and a worldwide shift of pharmacy profession from product-oriented to patient-oriented services is 
one of the dynamics of the profession. ${ }^{8,9}$ To meet these new challenges and responsibilities, pharmacy practitioners need to stay competent throughout their career and update their knowledge and skills to perform the new responsibilities effectively. ${ }^{2}$ This highlights the need of CPE program in supporting the role of pharmacy practitioners in different health care settings. ${ }^{9-11}$ In the context of Nepal, initiation of CPE program to maintain and improve knowledge and skills is largely self-directed and voluntary. A multicenter study in community pharmacy of Nepal showed that all the participants were willing to participate in the CPE program and all of them felt that the program would help in improving their knowledge. Furthermore, majority of participants were interested in the program that would focus on common drugs and diseases. ${ }^{12}$ However, no such study has been documented from hospital setting to our knowledge.

The hospital pharmacy of Chtiwan Medical College Teaching Hospital (CMCTH) initiated the CPE program to pharmacy practitioners from mid-2016 in collaboration with Health Professionals Education and Research Centre (HPERC) of this hospital and is probably a novel initiation to hospitals of Nepal. Meeting pharmacy practitioners' needs and matching their preferences are important prerequisites for effective CPE program. Pharmacy practitioners are more likely to grasp information better when topics meeting their preferences are presented. ${ }^{8,10}$ Therefore, it is pivotal to incorporate the opinion of pharmacy practitioners toward such program in order to meet their individual expectations. ${ }^{13}$ The results of this baseline assessment will be a foundation for the development of CPE program and its implementation in future. This pilot study aims to assess the opinion of hospital pharmacy practitioners with respect to such program.

\section{Methods}

This single-center study was conducted among the pharmacists (4 years of Bachelor in Pharmacy) and pharmacy assistants (3 years of Diploma in Pharmacy) working in hospital pharmacy of CMCTH, Bharatpur, Nepal, in March 2017. Ethical approval for this study was obtained from the Institutional Review Committee of CMCTH and all participants provided an informed consent. At the time of this study, there were 10 pharmacists and 15 pharmacy assistants working in three different units (outpatient pharmacy, inpatient/ emergency pharmacy and operation theater pharmacy) of the hospital pharmacy. A structured questionnaire was developed in collaboration with the HPERC of the hospital based on previous studies. ${ }^{11,14-15}$ The questionnaire had three sections: 1) baseline characteristics (age, sex, academic qualification, current working area and working experience); 2) opinions of pharmacists and pharmacy assistants toward CPE program (topics needed to be covered; suitable methods for delivery; motivating and inhibiting factors; preferred length; suitable methods for evaluating the effectiveness); and 3) suggestions for improving CPE program. The second section of opinion questionnaire allowed multiple responses while pharmacist and pharmacy assistant needed to write their suggestions for improving CPE program in the third section. The questionnaire was pretested among a randomly selected pharmacist and a pharmacy assistant (not included in main study) and necessary changes were made accordingly. The final questionnaire was distributed among pharmacists and pharmacy assistants (three pharmacists were excluded in this study as they were facilitators of the program). The participants were properly instructed about the purpose of the study and queries related to questionnaire were clarified. The suggestions from the participants for the improvement of CPE program were summarized. Descriptive statistics that included frequency, percentage, central tendency and dispersion were determined using IBM SPSS 20 (IBM Corporation, Armonk, NY, USA). Shapiro-Wilk test was performed to confirm the normality of numeric variable (age and working experience), and, thus, their central tendency and dispersion were confirmed as median and interquartile range (IQR). All other categorical variables were expressed as frequency and percentage.

\section{Results}

The median (IQR) age of the study participants was 24 (22.25-26.75) years. The proportion of males and females was equal. Most of the participants $(14,70 \%)$ hold diploma degree in pharmacy. The median (IQR) duration of working experience was $0.70(0.20-4.25)$ years (Table 1$)$.

Topics related to skills development were highly preferred topics in CPE program, and this was true for

Table I Baseline characteristics of participants

\begin{tabular}{lll}
\hline Variables & Category & n (\%) \\
\hline Age (years) & & $24(22.25-26.75)^{*}$ \\
Sex & Male & $10(50.0)$ \\
& Female & $10(50.0)$ \\
Academic & Diploma in Pharmacy & $14(70.0)$ \\
qualification & Bachelor in Pharmacy & $6(30.0)$ \\
Current working & Outpatient pharmacy & $9(45.0)$ \\
area & Emergency/inpatient pharmacy & $9(45.0)$ \\
& Operation theater pharmacy & $2(10.0)$ \\
Working experience (years) & $0.70(0.20-4.25)^{*}$ \\
\hline
\end{tabular}

Note: *Median (interquartile range). 
three quarters of participants, closely followed by recent innovations in pharmacy practice (65\%). Majority of the participants believed that live (in-person) presentations $(80 \%)$ and small group discussion $(60 \%)$ were the most suitable methods for delivery. Regarding motivating factors to participate in CPE program, most of the participants felt that improving knowledge (75\%), improving skills $(60 \%)$ and keeping up-to-date in latest information $(60 \%)$ were the major factors to encourage participation. The study also highlighted some inhibiting factors to attend in the program, with the foremost factor being lack of time, which was mentioned by three quarters of participants. Other common factors included structural problems (35\%), and poor quality and methods of delivery (30\%). The suggestion for CPE program for $>6$ hours per month was made by $70 \%$ of participants. More than half of the participants (11, 55\%) believed that face-to-face interview was the most suitable method for evaluating the effectiveness, while $45 \%$ of them mentioned practical exam (Table 2).

Some of the common suggestions for improving CPE program were allocation of separate time (30\%) for the program, assessing baseline knowledge and skills of the participants along with delivery of quality materials in an understandable way (25\%), motivation from management to participate in program (20\%) and conduction of seminar/ workshop involving national and international facilitator and participants (15\%) (Table 3).

\section{Discussion}

This study assesses the opinion of hospital pharmacy practitioners regarding CPE program, which is probably not common in Nepal. Topic related to skills development and recent innovations in pharmacy practice were the most common topics preferred by hospital pharmacy practitioners in our study. Currently, hospital and community pharmacy practitioners of Nepal are involved in various services such as patient counseling, blood pressure monitoring, medication record keeping, medicine information, first aid treatment, vaccination, face-to-face training of inhaler technique, reduction of prescription errors and telepharmacy, ${ }^{16-23}$ which are related to skill development and innovation in pharmacy practice. Our results might be the impact of such growing practice. A multicenter study in community pharmacy of Nepal showed that a majority of participants were interested on topics related to common drugs and diseases. ${ }^{12}$ The pharmacists of United Arab Emirates (UAE) were also more interested in innovation in disease management, innovation in pharmacy practice and skills development topics. ${ }^{15}$ Similarly, the pharmacists of Egypt and Qatar had also shown highest interest
Table 2 Opinion of participants toward the CPE program

\begin{tabular}{|c|c|c|}
\hline Questions & Responses of participants & n (\%) \\
\hline \multirow{5}{*}{$\begin{array}{l}\text { What are the topics } \\
\text { necessary to be covered } \\
\text { in the CPE program? }\end{array}$} & Related to skills development & I $5(75.0)$ \\
\hline & $\begin{array}{l}\text { Recent innovations in pharmacy } \\
\text { practice }\end{array}$ & $13(65.0)$ \\
\hline & Related to regulatory & $6(30.0)$ \\
\hline & requirements & \\
\hline & Related to disease management & $7(35.0)$ \\
\hline \multirow{5}{*}{$\begin{array}{l}\text { Which of the methods do } \\
\text { you believe are suitable } \\
\text { for the CPE program? }\end{array}$} & Live (in-person) presentations & $16(80.0)$ \\
\hline & Audio/video & $6(30.0)$ \\
\hline & Printed materials/handout & $5(25.0)$ \\
\hline & Small group discussion & $12(60.0)$ \\
\hline & Online information & $6(30.0)$ \\
\hline \multirow{8}{*}{$\begin{array}{l}\text { What are the motivating } \\
\text { factors for participating in } \\
\text { the CPE program? }\end{array}$} & Improve knowledge & $13(65.0)$ \\
\hline & Improve skills & $12(60.0)$ \\
\hline & Keeping up-to-date in latest & $12(60.0)$ \\
\hline & information & \\
\hline & Job satisfaction & $4(20.0)$ \\
\hline & Requirement for promotion & $3(15.0)$ \\
\hline & Active participation & $6(30.0)$ \\
\hline & $\begin{array}{l}\text { Curiosity about getting new } \\
\text { scientific information }\end{array}$ & $10(50.0)$ \\
\hline \multirow{5}{*}{$\begin{array}{l}\text { What are the inhibiting } \\
\text { factors for participating in } \\
\text { the CPE program? }\end{array}$} & Lack of time & $15(75.0)$ \\
\hline & $\begin{array}{l}\text { Poor quality and methods of } \\
\text { delivery }\end{array}$ & $6(30.0)$ \\
\hline & Structural problems & $7(35.0)$ \\
\hline & Conflict of interest & $3(15.0)$ \\
\hline & $\begin{array}{l}\text { Others (tiredness, uninteresting } \\
\text { topics) }\end{array}$ & $2(10.0)$ \\
\hline \multirow{3}{*}{$\begin{array}{l}\text { What is your preferred } \\
\text { length of the CPE } \\
\text { program per month? }\end{array}$} & $3-6$ hours & $6(30.0)$ \\
\hline & $9-12$ hours & $7(35.0)$ \\
\hline & More than 12 hours & $7(35.0)$ \\
\hline \multirow{5}{*}{$\begin{array}{l}\text { Which methods are } \\
\text { suitable for evaluating the } \\
\text { effectiveness of the CPE } \\
\text { program? }\end{array}$} & Practical exam & $9(45.0)$ \\
\hline & Written exam & $3(15.0)$ \\
\hline & Face-to-face interview & II $(55.0)$ \\
\hline & Feedback & $7(35.0)$ \\
\hline & Others (quiz contest) & $2(10.0)$ \\
\hline
\end{tabular}

Abbreviation: CPE, Continuing Pharmacy Education.

Table 3 Suggestions of participants for improving CPE program

\begin{tabular}{ll}
\hline Participants suggestion & $\mathbf{n}(\%)$ \\
\hline Allocation of separate time for CPE program & $6(30.0)$ \\
Accesses the baseline knowledge and skills of participants & $5(25.0)$ \\
and deliver quality materials in an understandable way & \\
accordingly & \\
Motivation from management to participate in CPE & $4(20.0)$ \\
program & \\
Conduct seminar/workshop involving national and & $3(15.0)$ \\
international facilitators and participants & \\
Create friendly environment in CPE program & $2(10.0)$ \\
Separate rooms for CPE program & $2(10.0)$ \\
Proper coordination among the staffs & $2(10.0)$ \\
Facilitate active participation in CPE program & $2(10.0)$ \\
Focus on practical aspects & I (5.0) \\
Proper organization of CPE program & I (5.0) \\
Used multiple approach for delivery of CPE program & I (5.0) \\
Continued need assessment of participants & I (5.0) \\
Include interesting topics in CPE program & I (5.0) \\
\hline
\end{tabular}

Abbreviation: CPE, Continuing Pharmacy Education. 
on topics related to therapeutics and clinical skills. ${ }^{14,24}$ But, Texan pharmacists gave more preference on medication error reduction and management of high cholesterol. ${ }^{25}$ Likewise, Flemish community pharmacists had chosen topics related to pharmaceutical care including information provision on drug issue, detecting problems at the counter, drugs during pregnancy, pediatric diseases and polypharmacy in the elderly in CPE courses. ${ }^{11}$ Another study revealed that pharmacists and pharmacy technicians were interested in sepsis and targeted antimicrobial therapy, and common infections in the critically ill patients. ${ }^{26}$ It is clear from the aforementioned evidences that the topic preferences of pharmacists and pharmacy assistants vary according to their needs, which in turn depend upon their working areas and related responsibilities. Therefore, continued need assessments are necessary for ensuring effectiveness of CPE program. In our study, participants mentioned that live (in-person) presentations was the most suitable method for delivery of CPE program, followed by small group discussion. Other studies have also reported similar findings. ${ }^{14,24}$ In contrast to this, the pharmacists of UAE were more satisfied with interactive workshop and computer/internet-based materials, while the live (in-person) presentations was the third preferred format of their CPE program. ${ }^{15}$ Several factors influence the participation in CPE program. Our participants acknowledged improving knowledge, improving skills and keeping up-to-date information as the common motivating factors to participate in CPE program while lack of time was mentioned as the major inhibiting factor. In contrast to our findings, receiving a syllabus and pleasant learning were perceived to be the strong motivating factors for attending CPE courses among Flemish community pharmacists while uninteresting subject was the most common inhibiting factor. Other imbibing factors identified in Flemish study were distance to the classes, lack of time and family constraints. ${ }^{14}$ The Qatar community and hospital pharmacists reported that poor timing and excessive workload were major obstacles for participating in CPE program. ${ }^{24}$ The pharmacists in England also reported time as a major barrier to participate in CPE activities. ${ }^{27}$ The Australian community pharmacists identified lack of time, inaccessibility and irrelevance of content as primary barriers to participate in CPE program. ${ }^{28}$ Inherent enthusiasm, workplace challenges and peer interaction were strong incentives for such program among pharmacists of Egypt and Qatar, in both hospital and community settings. ${ }^{14,24}$ Our participants preferred $>6$ hours of CPE program per month. In sharp contrast to this, majority of Texan pharmacists had preferred courses of duration up to 4 hours. ${ }^{25}$ In our study, more than half of the participants opined that face-to-face interview was the suitable method for evaluating the effectiveness of CPE program while written exam and quiz contest were the leastpreferred methods. Incorporation of pharmacy practitioners' suggestions is necessary for improving the program and for ensuring that the educational needs of the pharmacy practitioners are met in terms of requirements. Our participants suggested allocation of separate time for CPE program, as lack of time was one of the top perceived barriers to participate in the program. The second common suggestion was to assess the baseline knowledge and skills of participants and deliver quality materials in an understandable way. Motivation from management was another factor that could promote participation in CPE program. The Australian community pharmacist believed that continue education must be affordable, and use of integrated models can optimize efficacy for participants. ${ }^{29}$ Similarly, other study participants suggested that utilization of a wide variety of flexibly delivered programs supplemented with in-depth workshops is necessary for improving uptake of CPE program. ${ }^{28}$

Our pilot study adds definite value to existing literature because of its preliminary nature. However, it consisted of a small number of participants, and hence, the generalizability of the data for all Nepalese hospital pharmacy practitioners remains inadequate. The data in this study are subjective and rely on self-reported information. Therefore, we recommend nationwide survey involving pharmacy practitioners working in different health care settings.

\section{Conclusion}

We assessed the opinion of pharmacy practitioners with respect to $\mathrm{CPE}$ program working in the hospital pharmacy of CMCTH and upgraded the program accordingly to meet their expectations. Majority of participants suggested lack of time as a major obstacle to participate in the program. Therefore, authorities must take steps to manage time to involve in CPE program.

\section{Acknowledgments}

The authors are grateful to Mr. Pradeep Poudel for his help during the literature search. They are equally grateful to the pharmacy practitioners of Chitwan Medical College Teaching Hospital for their valuable participation in this study, and would also like to thank Mr. Santosh Sigdel, Senior Lecturer, Boston International College, Chitwan, Nepal, for English editing.

\section{Disclosure}

The authors report no conflicts of interest in this work. 


\section{References}

1. International Pharmaceutical Federation. FIP Statement of Professional Standards Continuing Professional Development. The Hague: FIP; 2002.

2. American College of Clinical Pharmacy, Burke JM, Miller WA, et al. Clinical pharmacist competencies. Pharmacotherapy. 2008;28(6): 806-815.

3. Rouse MJ. Continuing professional development in pharmacy. Am J Health Syst Pharm. 2004;61(19):2069-2076.

4. Driesen A, Verbeke K, Simoens S, Laekeman G. International trends in lifelong learning for pharmacists. Am J Pharm Educ. 2007;71(2):52.

5. Vlasses PH. Pharmacy continuing education: 40 years ago to now. Ann Pharmacother. 2006;41(10):1854-1856.

6. Carpentino J. Mandatory updating -a lifetime of commitment. Nurs Times. 1991;87(48):53-55.

7. Thomson O'Brein MA, Freemantle N, Oxman AD, Wolf F, Davis DA, Herrin J. Continuing education meetings and workshops: effects on professional practice and health care outcomes. Cochrane Database of Syst Rev. 2001;2:CD003030.

8. Schindel TJ, Kehrer JP, Yuksel N, Hughes CA. University-based continuing education for pharmacists. Am J Pharm Educ. 2012;76(2):20.

9. Jorgenson D, Lamb D, MacKinnon NJ. Practice change challenges and priorities: A national survey of practising pharmacists. Can Pharm J. 2011;144(3):125-131.

10. Driesen A, Leemans L, Baert H, Laekeman G. Flemish community pharmacists' motivation and views related to continuing education. Pharm World Sci. 2005;27(6):447-452.

11. Tran D, Tofade T, Thakkar N, Rouse M. US and international health professions' requirements for continuing professional development. $A m$ J Pharm Educ. 2014;78(6):129.

12. Poudel A, Khanal S, Alam K, Palaian S. Perception of Nepalese Community Pharmacists Towards Patient Counseling and Continuing Pharmacy Education Program: A Multicentric study. J Clin Diagn Res. 2009;3(2):1408-1413.

13. Strickland-Hodge B. Continuing professional development goes handin-hand with pharmacy practice. Pharm Pract. 2008;18(5):173-177.

14. Mohamed Ibrahim OH. Assessment of Egyptian pharmacists' attitude, behaviors, and preferences related to continuing education. Int J Clin Pharm. 2012;34(2):358-363.

15. Hasan S. Continuing education needs assessment of pharmacists in the United Arab Emirates. Pharm World Sci. 2009;31(6):670-676.
16. KC B, Alrasheedy AA, Ibrahim MI. Do community pharmacists in Nepal have a role in adverse drug reaction reporting systems?. Australas Med J. 2013;6(2):100-103.

17. Mishra P, Subish P, Upadhyay DK, Bista S, Alam K, Bhandari RB Medication counseling center in a teaching hospital. J Nepal Med Assoc. 2005;44(160):129-134.

18. Sharma S, KC B, Alrasheedy AA, Kaundinnyayana A, Khanal A. Impact of community pharmacy-based educational intervention on patients with hypertension in Western Nepal. Australas Med J. 2014;7(7):304-313.

19. Gyawali S, Rathore DS, Adhikari K, Shankar PR, Vikash KK, Basnet S. Pharmacy practice and injection use in community pharmacies in Pokhara city, Western Nepal. BMC Health Serv Res. 2014;14:190.

20. Poudel RS, Piryani RM, Shrestha S, Prajapati A. Benefit of hospital pharmacy intervention on the current status of dry powder inhaler technique in patients with asthma and COPD: a study from the Central Development Region, Nepal. Integr Pharm Res Pract. 2017;6:7-13.

21. Poudel RS, Shrestha S, Piryani RM, Prajapati A, Khatiwada D. Face-toface training as an effective approach for teaching rotahaler technique in newly diagnosed patients of asthma and COPD: a pilot study. J Nepal Med Assoc. 2015;53(198):150-152.

22. Poudel RS, Piyani RM, Shrestha S, Prajapati A, Adhikari B. Prescription errors and pharmacist intervention at outpatient pharmacy of chitwan medical college. JCMC. 2015;5(12):20-24.

23. Poudel RS, Shrestha S, Bhatta P, Piryani RM. Do face-to-face training and telephonic reminder improve dry powder inhaler technique in patients with COPD?. Int J Telemed Appl. 2017;2017:5091890.

24. Wilbur K. Continuing professional pharmacy development needs assessment of Qatar pharmacists. Int J Pharm Pract. 2010;18(4):236-241.

25. Alkhateeb FM, Attarabeen OF, Alameddine S. Assessment of texan pharmacists' attitudes, behaviors, and preferences related to continuing pharmacy education. Pharm Pract (Granada). 2016;14(3):769.

26. Awad NI, Bridgeman MB. Continuing-education program planning: tips for assessing staffeducational needs. Am J Health Syst Pharm. 2014;71(19): $1616-1619$.

27. Ward PR, Seston EM, Wilson P, Bagley L. Perceived barriers to participating in continuing education: the views of newly registered community pharmacists. Int J Pharm Pract. 2000;8(3):217-224.

28. Marriott JL, Duncan GJ, Mc Namara KP. Barriers to pharmacist participation in continuing education in Australia. Pharm Educ. 2007;7(1):11-17.

29. Mc Namara KP, Marriott JL, Duncan GJ. What makes continuing education effective: perspectives of community pharmacists. Int $J$ Pharm Pract. 2007;15(4):313-317.
Integrated Pharmacy Research and Practice

\section{Publish your work in this journal}

Integrated Pharmacy Research and Practice is an international, peer-reviewed, open access, online journal, publishing original research, reports, reviews and commentaries on all areas of academic and professional pharmacy practice. This journal aims to represent the academic output of pharmacists and pharmacy practice with particular focus on integrated care. All papers are carefully

\section{Dovepress}

peer reviewed to ensure the highest standards as well as ensuring that we are informing and stimulating pharmaceutical professionals. The manuscript management system is completely online and includes a very quick and fair peer-review system, which is all easy to use. Visit http://www.dovepress.com/ testimonials.php to read real quotes from published authors. 